\title{
Future Family Business Owners Can Learn to Manage Conflict
}

\author{
Ritch Sorenson (University of St. Thomas)
}

KEYWORDS: Management of Companies \& Enterprises, Management, Teaching Methods, Family Business.

Conflict is inevitable in family-run businesses. Learning how to manage it and channel it productively is an important skill for entrepreneurship students who may someday manage their own family's firm.

This classroom exercise helps them identify productive and non-productive ways to disagree. It is based on our own research about how conflict affects owners of small to medium sized businesses (Sorenson, 1999). Students first complete a questionnaire that assesses how their families handle conflict (Rahim, 1983) and then compute scores to develop a conflict profile. The professor then discusses the theoretical framework on which the measure was based, and discusses five styles of conflict management and how those approaches can affect business and family outcomes. Finally, the professor asks students to share how their own families utilized the five styles and what happened as a result.

\section{INTRODUCTION}

Each business family develops its own approach for resolving differences. Research shows that the approach to managing conflict affects family relationships and business performance (Sorenson, 1999). To help students understand the impact of different approaches, you will 1) ask students to complete a questionnaire about the conflict management approach used in their family, 2) discuss the five conflict management approaches and summarize research that reveals outcomes associated with each style, and 3) obtain examples from class members regarding each style and its impact.

\section{STEP 1: COMPLETE THE QUESTIONNAIRE}

Distribute the questionnaire (download Exhibit 1), which is a short version of the original questionnaire developed

by Rahim (1983, see also Sorenson, 1999), and asks students to compute scores using the score sheet. The profile provides a summary of approaches most and least used.

If students have a family business, ask them to focus on members of the business family when completing the survey. Students might want to ask others in their family to fill out the survey to compare answers.

\section{STEP 2: CALCULATE SCORES}

The professor distributes the Differences Inventory Scorecard (download Exhibit 2) and asks students to transfer numeric ratings from their survey to the scorecard and compute total scores. Score totals reveal a profile for managing differences representing the five approaches to conflict: accommodate, avoid, compromise, compete and collaborate.

\section{STEP 3: DISCUSSION OF CONFLICT MANAGEMENT APPROACHES}

The professor then introduces the conflict framework (download Exhibit 3), which was adapted from Rahim (1983). Each of the five approaches has a different impact on possible solutions and relationships.

- Avoid. The failure to address conflict, which has a negligible or negative impact on family relationships and problem solving (and business performance).

- Compete (Dominate). Manages differences by forcing a solution, often described as a win-lose approach. This forcing approach often makes family relationships worse and discourages solutions acceptable to everyone. The result is poor business performance.

- Compromise. Involves each party giving up
Copyright ( 2017 The Authors. Entrepreneur \& Innovation Exchange is published at EIX.org. This is an open access article under the terms of the Creative Commons Attribution-NoDerivs License, which permits use and distribution in any medium, provided the original work is properly cited and no modifications or adaptations are made. View EIX.org Authorship Terms at https://eix.org/terms
FamilyBusiness 
something to find an acceptable solution that maintains working relationships and acceptable outcomes.

- Accommodate (Oblige). The opposite of competition. This approach puts relationships and the needs of others ahead of finding the best solution. Family relationships may improve or at least stay tranquil, but the solutions may be unsatisfactory, with no impact on business performance.

- Collaborate (Integrate). Unlike compromise, this approach attempts to find the best solution for everyone involved (a "win-win") and to sustain positive relationships. Some approach this as a "win-win or no deal." This approach sustains family relationships and finds optimal solutions, which help the business the most.

Next, the professor discusses the scores and indicates that scores for Collaborate, Accommodate and Compromise tend to correlate. Scores for Compete and Avoid also tend to go together. This means that when Compete and Avoid scores are high, Collaborate, Accommodate, and Compromise scores tend to be low and vice versa.

Then, the class discusses the scores. The professor summarizes the score profile for each family and its impact, and students are asked to volunteer whether their ratings fit one of the two profiles and to make observations about its impact.

Discuss that family and business often overlap greatly in family-run firms, and the approach for managing differences could influence both business and family outcomes. Then, discuss the study in Step 4 below to illustrate potential outcomes.

\section{STEP 4: DISCUSSION OF OUTCOMES IN SMALL FAMILY BUSINESSES}

The 1999 study (Sorenson) surveyed 59 family businesses. Key findings included:

- Competitive and avoidance styles often coexist and can trigger each other. The "avoiders" go a long time without expressing their differences, and as a result the tensions mount and cause a blow up, resulting in competition afterwards. The Sorenson (1999) study suggests that a cycle of avoidance and competition can result in poor family relationships and low business performance. Competition focuses on strategically withholding information and using tactics to get others to give in or give up (Lewicki \& Litterer, 1985). In family-owned businesses "ownership authority" is often used to solve disputes (Dyer, 1986) and if the owner is a party to the conflict, the solutions often make the owner happy but not the rest of the family. (Sorenson, 1999).

- The collaborate, compromise and accommodate styles can lead to harmony. These styles represent an attempt to sustain good relationships. Business families that use these approaches likely have good relationships. However, the collaborative approach resulted in both positive relationships and superior business performance.

- Formal meetings build collaboration into the business. (See discussion section in Sorenson, 1999). Professionalized business practices -- regular, structured business and owner meetings -- fosters more collaboration. Holding these meetings provides the ideal setting to address issues and make plans. These meetings could include annual strategic planning meetings and weekly or monthly coordination and planning meetings.

- Families that are not accustomed to collaborating may need the help of a professional advisor. The transition from decision-making within family structure to a collaborative group is a tough transition for many business families. Typically, the advisor facilitates discussions and helps the owning family to develop listening and speaking skills that promote problem-solving.

\section{STEP 4: DISCUSSION}

Drawing on the discussion of outcomes described above, ask students to look at their survey results and share stories or illustrations of how their typical approach to managing conflict impacts family interactions, decisions and relationships. Then discuss how regular family meetings to coordinate and plan might improve how differences are handled. 


\section{CONCLUSION: NEXT STEPS}

Best governance practices promote a collaborative approach. Organizing a family decision-making group is not always easy-especially in busy families. Here are some suggestions:

- Get in the habit of scheduling regular owner meetings and following an agenda.

- Keep minutes of discussions and decisions.

- Make informed decisions. Identify the problem, access relevant information and discuss before making decisions.

- Develop agreements and keep electronic records to which everyone has access.

- Hire a facilitator, if for no other reason than to help keep you and your family on track. Some families start with work on communication (active listening and use of "I" statements), but helping to guide and structure early meetings can be a way to create change in how the family makes decisions together.

After adopting some of these best governance practices, the owning family might consider taking a followup inventory about their differences - to see how much implementing these practices may have made a difference.

\section{REFERENCES}

Dyer, W.G. (1986) Cultural Change in Family Firms: Understanding and managing business and family transition. San Francisco: Jossey-Bass.

Lewicki, R.J. \& Litterer, J.A. (1985) Negotiation. Homewood, Illinois: Irwin.

Seymour, K.C. (1993) Intergenerational relationships in the family firm: The effect of leadership on succession Family Business Review, 6 (3), 263-281.

Sorenson, R.L. (1999) Conflict Management Strategies Used by Successful Family Businesses. Family Business Review, 12; (4) 325-338.

Rahim, M.A. (1992) Managing conflict in organizations. Westport CT: Praeger.

Rahim, M.A. (1983) A Measure of styles of handling interpersonal conflict. Academy of Management Journal, 26(2), 268-376.

\section{More ideas}

College business professors looking for more ideas to enrich the classroom experience can find them here (https://familybusiness.org/eix-in-class) .

Additional Search Terms: entrepreneurship courses, teaching ideas, teaching resources, classroom ideas, entrepreneurship classes, business schools, business school classes, entrepreneurship students, professors 